\title{
Isolasi, karakterisasi, dan uji aktivitas sebagai antibakteri ekstrak aseton biji mangga golek (Mangifera indica Linn)
}

\author{
Ayuning Tiyas, Sutrisno*, Dedek Sukarianingsih \\ Universitas Negeri Malang, Jl. Semarang No. 5 Malang, Jawa Timur, Indonesia \\ *Penulis korespondensi, Surel: sutrisno.fmipa@um.ac.id
}

Paper received: Paper received: 01-02-2022; revised: 15-02-2022; accepted: 28-02-2022

\begin{abstract}
Abstrak
Telah dilakukan penelitian tentang isolasi dan karakterisasi ekstrak aseton biji mangga golek (Mangifera indica Linn) serta uji aktivitasnya sebagai antibakteri. Isolasi dilakukan dengan maserasi dan sokhletasi menggunakan aseton diperoleh cairan kental berwarna putih kekuningan. Ekstrak biji mangga ini larut dalam air, metanol, aseton, serta etil asetat, tidak larut dalam kloroform dan heksana, positif pada uji golongan fenolik, flavonoid, terpenoid, saponin, dan tanin, serta aktif sebagai antibakteri kategori tinggi terhadap bakteri Staphylococcus aureus dan Escherichia coli. Pemurnian pada ekstrak biji mangga menggunakan kromatografi kolom gravitasi dengan eluen kloroform : etil asetat (4:1). Hasil pemurnian diperoleh Komponen B yang berupa padatan putih. Komponen ini mempunyai titik lebur $41-43^{\circ} \mathrm{C}$, larut dalam heksana, kloroform, dan etil asetat; memudarkan warna larutan brom; positif pada uji golongan senyawa saponin; memiliki $\lambda$ maks $224,20 \mathrm{~nm}$ dan $\lambda$ maks $338,60 \mathrm{~nm}$; memiliki vibrasi ulur $\mathrm{C}=0$ ester, $\mathrm{C}-\mathrm{O}$ ester, dan vibrasi ulur $\mathrm{C}=\mathrm{C}$, serta aktif sebagai antibakteri kategori sedang terhadap bakteri Staphylococcus aureus dan Escherichia coli.
\end{abstract}

Kata kunci: biji mangga golek (Mangifera indica Linn); antibakteri; ekstrak aseton.

\section{Pendahuluan}

Mangga merupakan salah satu jenis tanaman yang melimpah di Indonesia. Salah satu jenis mangga yang sering ditemukan di Indonesia adalah mangga golek. Pemanfaatan tanaman mangga hanya terbatas pada daging buahnya. Buah mangga dapat dikonsumsi langsung ataupun dalam bentuk olahan. Sisa pengolahan dari buah mangga adalah bijinya. Biji merupakan produk akhir dari metabolisme tumbuhan. Biji merupakan produk penting dalam regenerasi tumbuhan sebagai cikal bakal perkembangbiakan tumbuhan agar memiliki sifat yang sama seperti induknya. Di dalam biji mangga diduga mengandung komponen unik yang dapat dieksplorasi manfaatnya.

Beberapa penelitian tentang biji mangga telah banyak dilakukan. Penelitian Abdalla (2007) menunjukkan adanya senyawa fenolik yang terkandung dalam ekstrak metanol biji mangga Mesir mencapai 79,5 \% dari $100 \mathrm{~g}$ berat biji kering. Kabuki et al (2000) melaporkan bahwa ekstrak etanol biji mangga dapat menghambat 18 jenis bakteri dari 43 total jenis bakteri patogen dalam makanan dengan metode delusi agar. Karakteristik senyawa antibakteri dalam biji mangga disebabkan karena adanya senyawa fenolik. Kabuki et al (2000) melaporkan bahwa analisis HPLC menunjukkan adanya dua fraksi dengan puncak serapan maksimum 275 nm memiliki aktivitas antibakteri. Jenis bakteri yang mampu dihambat oleh ekstrak etanol tersebut adalah Staphylococcus aureus dan bakteri Escherichia coli. Tian et al (2009) melaporkan bahwa pelarut dengan kepolaran tinggi dapat mengekstrak senyawa fenolik dalam biji mangga lebih banyak dibandingkan pelarut non polar. Kadar fenolik yang terekstrak dengan etil asetat mencapai 72,69 \% sedangkan dengan eter diperoleh 2,49\%.

Penelitian ini bertujuan untuk: 1) mengisolasi komponen dalam biji mangga golek (Mangifera indica Linn) dengan metode maserasi dan sokhletasi menggunakan pelarut aseton; 
2) mengkarakterisasi komponen hasil isolasi ekstrak aseton biji mangga golek (Mangifera indica Linn); dan 3) menentukan aktivitas komponen hasil isolasi dari ekstrak aseton biji mangga golek (Mangifera indica Linn) sebagai antibakteri terhadap bakteri Staphylococcus aureus dan Escherichia coli.

Pemilihan pelarut aseton yang bersifat semipolar diharapkan mampu menjebak senyawa-senyawa yang aktif sebagai antibakteri. Selain dilihat dari sifat kepolarannya, pemilihan pelarut aseton dilihat dari berbagai kelebihan dari aseton. Aseton memiliki wujud cair yang tidak berwarna dan memiliki kepolaran yang relatif tinggi hal tersebut ditandai dengan mudah larut dengan sempurna dalam air, mendidih pada suhu $56,2{ }^{\circ} \mathrm{C}$ dan mudah menguap pada suhu ruangan (memiliki volatilitas yang tinggi). sifat volatilitas yang dimiliki oleh aseton diharapkan dapat memudahkan pada proses pemisahan antara ekstrak dengan pelarut. Toksisitas yang dimiliki oleh aseton tergolong rendah, hal ini dibuktikan dengan nilai LD 50 nya sebesar $3000 \mathrm{mg} / \mathrm{kg}$ berat badan mencit (MSDS, 2013).

\section{Metode}

\subsection{Alat dan Bahan}

2.1.1. Alat. Seperangkat alat gelas, neraca digital merk Durascale DAB 200 dengan ketelitian $0,001 \mathrm{~g}$, neraca analitik triple beam dengan ketelitian $0,1 \mathrm{~g}$, seperangkat alat maserasi, seperangkat alat rotary evaporator merk Buchi Waterbath B-480, seperangkat alat kromatografi lapis tipis, seperangkat alat kromatografi kolom gravitasi, autoclave, laminar air flow, jangka sorong, Fischer Scientific Melting Point Apparatus, seperangkat spektrofotometer UV merk Shimadzu 1601, seperangkat spektrofotometer FTIR merk Shimadzu IR-prestige 21.

2.1.2.Bahan. Biji mangga golek (yang peroleh dari pasar Gadang, Kota Malang), heksana, kloroform, etil asetat, dan metanol, akuades, larutan natrium hidroksida alkoholis 0,5 M, iod, silika gel 60, brom, karbon tetraklorida, kertas lakmus, plat KLT dengan lapisan silika gel $60 \mathrm{~F}_{254}$ pada plat, cotton bud, nutrien agar (NA), nutrien cair (NC), ampisilin, larutan standar Mc Farland 0,5, bakteri biakan murni Staphylococcus aureus dan Escherichia coli (keduanya diperoleh di Laboratorium Mikrobiologi Jurusan Biologi FMIPA, Universitas Negeri Malang).

\subsection{Percobaan}

2.2.1. Preparasi Sampel. Sampel biji mangga dikupas kulit buahnya, dan dipisahkan daging buah dengan bijinya. Biji yang diperoleh kemudian dicuci hingga bersih, dipotong kecilkecil (dirajang), dikeringkan dalam oven pada suhu $45-50{ }^{\circ} \mathrm{C}$ selama 48 jam. Proses pengeringan dilakukan hingga diperoleh berat konstan kemudian dihaluskan dengan cara ditumbuk sampai menjadi serbuk dan diayak.

2.2.2. Isolasi Sampel. Sebanyak $250 \mathrm{~g}$ biji mangga diekstraksi dengan maserasi dengan $400 \mathrm{~mL}$ pelarut aseton selama $3 \times 24$ jam. Hasil maserasi disaring setiap 1 x 24 jam dan residu diremaserasi dalam $400 \mathrm{~mL}$ aseton kemudian filtrat didiamkan selama 72 jam hingga muncul padatan berwarna putih kekuningan (Fraksi I). Fraksi I dipisahkan dengan penyaringan menggunakan kertas saring untuk memisahkan filtrat dari padatan berwarna putih kekuningan. Filtrat di evaporasi menggunakan alat rotary evaporator hingga diperoleh ekstrak pekat aseton biji mangga golek (Fraksi II). Proses isolasi 
dilanjutkan dengan sokhletasi yaitu sebanyak 205,5 g (semua) residu 1 diletakkan pada timbel, dan di ekstrak menggunakan $700 \mathrm{~mL}$ aseton. Sokhletasi dilakukan secara terusmenerus dan dihentikan setelah diperoleh warna pelarut identik dengan warna aseton sebelum digunakan ekstraksi. Fraksi I hasil disaring untuk memisahkan filtrat dengan padatan putih kekuningan. Filtrat di evaporasi menggunakan alat rotary evaporator hingga diperoleh Fraksi II. Fraksi II kemudian digabung menjadi satu dengan Fraksi II hasil maserasi dan dihitung rendemennya.

2.2.3. Pemurnian Komponen Hasil Isolasi. 1) KLT pada Fraksi II, dilakukan dengan menotolkan sampel yang telah dilarutkan dalam aseton pada plat KLT kemudian dimasukan ke dalam chamber yang berisi eluen. Noda pada plat hasil elusi dianalisis dengan lampu $\mathrm{UV}_{254 \mathrm{~nm}}$ dan dilanjutkan dengan iod. 2) kromatografi kolom gravitasi dilakukan dengan mencampur sebanyak 50 gram silika gel 60 (0,063-0,0200 mm ) kode 7734 dengan kloroform sehingga diperoleh bubur silika dan dimasukkan ke dalam kolom gelas (diameter 2,5 cm) secara perlahan-lahan sambil dielusi dengan kloroform. Kolom silika dibuat hingga panjang $29 \mathrm{~cm}$; 2) Fraksi II dilarutkan dengan aseton dimasukkan diatas bubur silika dan dielusi dengan eluen yang dipilih. Fraksi-fraksi yang diperoleh kemudian ditampung dalam botol vial.

2.2.4. Karakterisasi Hasil Isolasi. Karakterisasi hasil isolasi dilakukan terhadap 1) wujud dan warna; 2) titik lebur menggunakan Fischer Scientific Point Apparatus; 3) kelarutan dalam berbagai pelarut organik (heksana, etil asetat, aseton , kloroform, dan metanol); 4) uji ketidakjenuhan dengan mereaksikan pada larutan brom dalam $\mathrm{CCl}_{4}$; 5) uji golongan senyawa bahan alam yang dilakukan adalah uji fenolik, flavonoid, tanin, terpenoid, dan saponin; 6) analisis menggunakan spektrofotometri UV; 7) interpretasi spektrum IR.

2.2.4.1. Wujud dan warna. Hasil isolasi dikarakterisasi wujud dan warna melalui pengamatan secara visual.

2.2.4.2. Titik lebur. Sedikit sampel diletakkan di atas kaca preparat kemudian diuji titik leburnya di atas hotplate pada alat Fischer Scientific Point Apparatus. Titik lebur sampel dicatat dari mulai lebur sampai melebur sempurna.

2.2.4.3. Kelarutan. Sebanyak 0,1 g sampel dilarutkan tetes demi tetes sampai $2 \mathrm{~mL}$ pelarut (heksana, kloroform, aseton, etil asetat, air, dan metanol) kemudian dikocok.

2.2.4.4. Uji ketidakjenuhan. Sebanyak 3 tetes larutan brom dalam $\mathrm{CCl}_{4}$ ditambah $1 \mathrm{~mL}$ sampel dalam kloroform. Uji positif adanya ikatan $\mathrm{C}=\mathrm{C}$ tidak jenuh non aromatik ditandai dengan memudarnya warna larutan brom.

2.2.4.5. Uji Fenolik. Sebanyak 0,1 g sampel dilarutkan dalam1 $\mathrm{mL}$ etil asetat, ditambahkan 1 mL larutan $\mathrm{FeCl}_{3}$ 1\% dikocok, dan diamati perubahan yang terjadi. Timbulnya warna ungu hingga biru tua menunjukkan uji positif untuk gugus fenolik (Edewor, et al, 2013).

2.2.4.6. Uji Flavonoid. Sebanyak 0,1 g sampel dilarutkan dalam $1 \mathrm{~mL}$ etil asetat, kemudian ditambah $1 \mathrm{~mL}$ larutan $\mathrm{NaOH} 2 \mathrm{M}$ dikocok, dan diamati. Timbulnya warna kuning hingga jingga menunjukkan uji positif untuk flavonoid (Roopalatha \& Nair, 2013). 
2.2.4.7. Uji Tanin. Sebanyak $0,1 \mathrm{~g}$ sampel dilarutkan dalam1 $\mathrm{mL}$ etil asetat, kemudian ditambah $1 \mathrm{~mL}$ larutan $\mathrm{FeCl}_{3} 5$ \% dikocok dan diamati. Timbulnya warna ungu hingga biru tua menandakan uji positif untuk tanin (Roopalatha \& Nair, 2013).

2.2.4.8. Uji Terpenoid. Sebanyak 0,1 g sampel dilarutkan dalam $1 \mathrm{~mL}$ kloroform, kemudian ditambah $1 \mathrm{~mL}$ kloroform dan $1 \mathrm{~mL}$ larutan $\mathrm{H}_{2} \mathrm{SO}_{4}$ pekat. Uji positif terpenoid ditandai dengan terbentuk cincin berwarna jingga hingga coklat (Edeoga et al, 2005).

2.2.4.9. Uji Saponin. Sebanyak 0,1 g sampel dilarutkan dalam $1 \mathrm{~mL}$ kloroform, kemudian ditambah $1 \mathrm{~mL}$ aquades dan 10 tetes larutan KOH 0,1 M kemudian dipanaskan, dan dikocok dengan kuat dan didiamkan selama 15 menit. Uji positif saponin ditandai dengan munculnya busa pada sampel yang bertahan hingga 15 menit (Edewor et al, 2013).

2.2.4.10. Interpretasi Spektrum UV. Sebanyak $50 \mathrm{mg}$ sampel dilarutkan dalam $10 \mathrm{~mL}$ heksana sehingga diperoleh konsentrasi 5000 ppm. Larutan ini selanjutnya dianalisis menggunakan spektrofotometer UV pada panjang gelombang 200-400 $\mathrm{nm}$ dengan blanko heksana.

2.2.4.11. Interpretasi spektrum IR. Sebanyak $1 \mathrm{mg}$ sampel dicampur dengan serbuk kering kalium bromida secara homogen kemudian digerus sampai kehalusan tertentu. Serbuk halus ini selanjutnya dibuat dalam bentuk lapisan tipis (pellet). Pellet ini dianalisis menggunakan spektrofotometer FT-IR pada bilangan gelombang 4000$400 \mathrm{~cm}^{-1}$.

2.2.5. Uji Aktivitas Antibakteri. (1) pembuatan media cair (NC), media padat (NA), dan sterilisasi alat, (2) pembuatan media murni bakteri; dan (3) uji daya hambat pada bakteri biakan murni (Staphylococcus aureus dan Escherichia coli) dalam media NC yang sudah distandarisasi dengan Mc Farland 0,5 dalam media NA yang diinokulasi kemudian dilubangi dengan alat bor khusus sehingga membentuk lubang atau sumur berdiameter $6 \mathrm{~mm}$. Sampel uji sebanyak $2 \mu \mathrm{L}$ diteteskan ke dalam sumuran kemudian diinkubasi ke dalam inkubator pada temperatur $37 \stackrel{\circ}{\mathrm{C}}$ selama $1 \times 24$ jam. Setelah $1 \times 24$ jam diameter zona bening pertumbuhan bakteri uji diukur menggunakan jangka sorong.

\section{Hasil dan Pembahasan}

Berdasarkan perlakuan preparasi hingga isolasi senyawa, diperoleh data kadar air dalam biji mangga golek sebesar 61,60\%, rendemen hasil ekstraksi 18,2 \%. Hasil ekstraksi (Fraksi I) yang memiliki endapan berwarna putih kekuniangan kemudian dipisahkan dengan penyaringan sehingga diperoleh filtrat coklat kekuningan (Fraksi II) dan padatan berwarna putih kekuningan (Fraksi III). Seluruh hasil ekstraksi ditimbang diperoleh Fraksi III sebanyak 8,6 g dan Fraksi II sebanyak 31,8 g dari 250 g serbuk biji mangga yang diekstraksi.

Analisis Fraksi II menggunakan KLT dilakukandengan menggunakan berbagai jenis eluen yaitu 1) kloroform (ekstrak tanpa dilarutkan dalam aseton); 2) kloroform (ekstrak yang dilarutkan dalam aseton); 3) kloroform : metanol (1:1); 4) heksana; 5) heksana: etil asetat (1:1); 6) etil asetat; 7) heksana : etil asetat (4:6); 8) heksana: etil asetat (3:7); 9) kloroform : etil asetat (4:1). Dari kromatogram hasil KLT dari berbagai eluen, campuran kloroform : etil asetat $(4: 1)$ menunjukkan pemisahan pada komponen paling baik. Eluen tersebut memiliki 
nilai $R_{\mathrm{f}}$ sebesar 0,14 untuk komponen pertama; kedua 0,54; ketiga 0,82; dan nilai $R_{\mathrm{f}}$ untuk komponen keempat sebesar 0,90. 2) kromatografi kolom gravitasi bertujuan untuk memisahkan komponen dalam Fraksi II dengan baik menggunakan eluen dari KLT. Proses KKG ini memerlukan waktu lebih dari 24 jam untuk memperoleh 179 fraksi. Fraksi yang diperoleh ditampung dalam botol vial dengan volume setiap botol vial sekitar $6 \mathrm{~mL}$. Hasil fraksinasi dengan KKG selanjutnya di analisis dengan KLT dengan eluen yang sama yaitu (kloroform : etil asetat (4:1)) untuk melihat pola komponen yang diperoleh.

Noda yang memiliki nilai $R_{\mathrm{f}}$ sama atau identik, akan digabung menjadi satu. Penggabungan fraksi 1-45 (memiliki noda yang identik) diperoleh 0,114 g setelah proses penguapan diberikan kode A dengan nilai $R_{\mathrm{fA} \text { noda } 1} 0,05$ dan $R_{\mathrm{fA} \mathrm{noda} 2} 2,16$. Fraksi 50-60 digabung menjadi satu diperoleh 0,019 g setelah proses penguapan diberikan kode $\mathrm{B}$ dengan nilai $R_{\mathrm{fB}}$ noda1 0,16 dan $R_{\mathrm{fB} \text { noda } 2}$ 0,58. Fraksi $65-85$ sebesar 0,017 g setelah proses penguapan diberikan kode C dengan nilai $R_{\mathrm{fC} \text { noda } 1} 0,16$ dan $R_{\mathrm{fC} \text { noda } 2}$ 0,54. Fraksi 90-125 diperoleh 0,008 g diberikan kode D dengan nilai $R_{\mathrm{fD} \text { noda } 1}$ 0,16 dan $R_{\mathrm{f} \mathrm{D} \mathrm{noda} 2}$ 0,60. Fraksi 110-179 diberikan kode E. Fraksifraksi yang telah digabung, kemudian di KLT kembali untuk mengetahui pola pemisahan yang diperoleh setelah proses penguapan. Fraksi-fraksi tersebut kemudian dihitung nilai $R_{\mathrm{f}}$ nya. Hasil analisis KLT pada Komponen B menunjukkan bahwa eluen (kloroform : etil asetat (4:1)) dapat memisahkan komponen dalam Fraksi II menggunakan metode kromatografi kolom gravitasi Karakterisasi pada Fraksi II.

Hasil pengamatan wujud dan warna menunjukkan bahwa Fraksi II berwujud cair kental, dan berwarna kening kecoklatan. Uji kelarutan Fraksi II dalam berbagai pelarut ditunjukkan pada Tabel 1.

Tabel 1. Hasil Uji Kelarutan Fraksi II dalam Berbagai Pelarut

\begin{tabular}{lll}
\hline Pelarut yang Digunakan & Tingkat Kelarutan & Keterangan \\
\hline Heksana & --- & Tidak Larut \\
Kloroform & +-- & Larut Sebagian \\
Etil Asetat & +++ & Larut Sempurna \\
Metanol & +++ & Larut Sempurna \\
Air & +++ & Larut Sempurna \\
\hline
\end{tabular}

Tabel 1. menunjukkan Fraksi II larut pada pelarut yang memiliki kepolaran yang relatif tinggi. Hasil uji kelarutan Fraksi II tidak larut dalam heksana, sedikit larut dalam kloroform, dan larut sempurna dalam etil asetat, metanol, dan air.

Hasil uji golongan senyawa pada Fraksi II positif pada uji fenolik, saponin, flavonoid, terpenoid, dan tanin. Hasil uji golongan senyawa pada Fraksi II ditunjukkan pada Tabel 2.

Tabel 2 Hasil Uji Golongan Senyawa pada Fraksi II

\begin{tabular}{lll}
\hline Golongan Senyawa & Hasil Uji & Keterangan \\
\hline Fenolik & Timbul warna biru tua & + \\
Saponin & Muncul busa permanen & + \\
Flavonoid & Larutan berwarna jingga & + \\
Terpenoid & Terbentuk cincin berwarna jingga & + \\
Tanin & Larutan berwarna biru tua & + \\
\hline
\end{tabular}


Pada pemurnian dengan kromatografi kolom gravitasi diperoleh Komponen $B$ yang berwujud padat dan berwarna putih. Komponen ini melebur pada $41-43^{\circ} \mathrm{C}$.

Hasil uji kelarutan menunjukkan Komponen $B$ larut sempurna dalam heksana, kloroform, dan etil asetat, namun tidak larut dalam metanol, dan air. Hasil uji kelarutan Komponen $B$ dalam berbagai pelarut ditunjukkan dalam Tabel 3.

Tabel 3 Hasil Uji Kelarutan Komponen B dalam Berbagai Pelarut

\begin{tabular}{lll}
\hline Pelarut yang Digunakan & Tingkat Kelarutan & Keterangan \\
\hline Heksana & +++ & Larut Sempurna \\
Kloroform & +++ & Larut Sempurna \\
Etil Asetat & +++ & Larut Sempurna \\
Metanol & -- & Tidak Larut \\
Air & --- & Tidak Larut \\
\hline
\end{tabular}

Hasil uji ketidakjenuhan menunjukkan Komponen $B$ positif memiliki ikatan ganda yang ditandai dengan melenyapkan warna larutan brom dalam $\mathrm{CCl}_{4}$. Warna awal larutan brom dalam $\mathrm{CCl}_{4}$ adalah oranye kecoklatan, namun setelah penambahan Komponen $B$ larutan tersebut menjadi tidak berwarna. Hal tersebut mengindikasikan bahwa dalam Komponen $B$ terdapat ikatan ganda karbon-karbon yang diadisi oleh brom.

Hasil uji golongan senyawa Komponen B ditunjukkan pada Tabel 4.

Tabel 4 Hasil Uji Golongan Senyawa Komponen B

\begin{tabular}{lll}
\hline Golongan Senyawa & Hasil Uji & Keterangan \\
\hline Fenolik & Tidak timbul warna hitam & - \\
Saponin & Muncul busa permanen & + \\
\hline
\end{tabular}

Analisis pada Komponen $B$ menggunakan spetrofotometer UV dengan dengan konsentrasi $5000 \mathrm{ppm}$. Spektrum UV yang diperoleh menunjukkan panjang gelombang maksimum lebih besar dari $210 \mathrm{~nm}$. Hal tersebut mengindikasikan bahwa senyawa dalam komponen B tersebut aktif UV dan terdapat sistem ikatan ganda di dalamnya. Spektrum UV komponen B ditunjukkan pada Gambar 1.

\section{Gambar 1 Spektrum UV Komponen B}

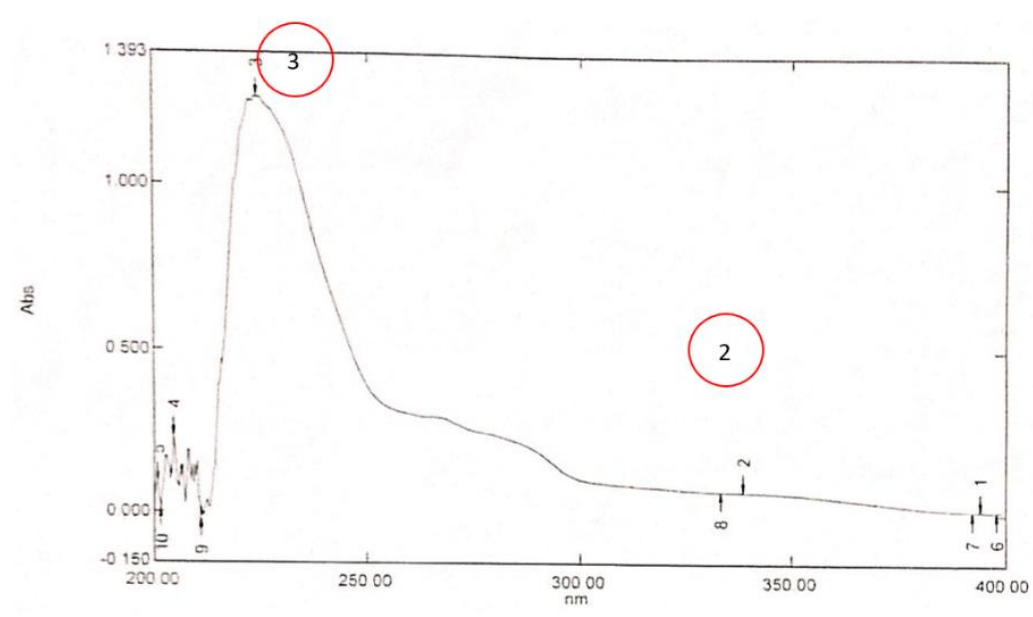


Spektrum UV Komponen $B$ menunjukkan adanya serapan kuat yang terjadi pada $\lambda_{\text {maks }}$ $224,20 \mathrm{~nm}$ dengan absorbansi 1,264 , dan pada $\lambda_{\text {maks }} 338,60 \mathrm{~nm}$ dengan absorbansi 0,068 . Puncak kedua dengan $\lambda_{\text {maks }} 224,20 \mathrm{~nm}$ yang mengindikasikan adanya transisi $\pi \rightarrow \pi^{*}$ akibat ikatan $C=C$ terkonjugasi. Identifikasi spektrum UV pada $\lambda_{\text {maks }} 224,20 \mathrm{~nm}$, dan $\lambda_{\text {maks }} 338,60 \mathrm{~nm}$, maka diduga dalam Komponen $B$ terdapat ikatan $\mathrm{C}=\mathrm{C}$ terkonjugasi, dan ikatan $\mathrm{C}=\mathrm{O}$.

Spektrum IR Komponen B memunculkan beberapa spektrum dan kemudian dianalisis. Hasil analisis dari spektrum yang muncul dapat digunakan untuk menginterpretasikan gugus fungsi dalam Komponen $B$. Setiap gugus fungsi memiliki pita serapan yang khas pada bilangan gelombang tertentu. Spektrum FTIR Komponen B ditunjukkan pada Gambar 2.

\section{Gambar 2 Spektrum FTIR Komponen B}

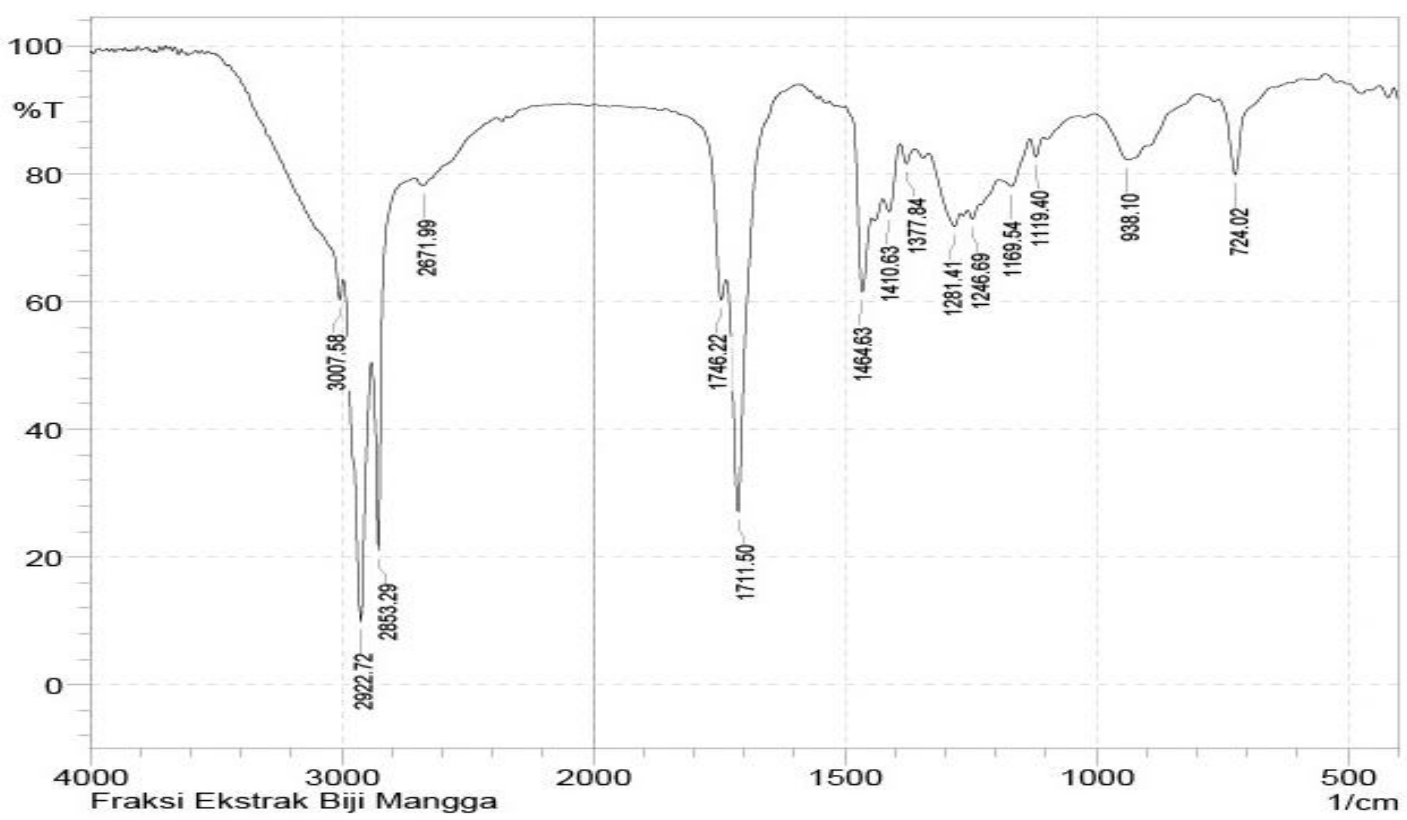

Spektrum IR tersebut menunjukkan pita serapan sedang pada bilangan gelombang antara 3100-3000 $\mathrm{cm}^{-1}$ mengindikasikan adanya ikatan $\mathrm{C}-\mathrm{H}$ (alkena). Pita serapan tajam dan kuat pada bilangan gelombang 3000-2850 $\mathrm{cm}^{-1}$ merupakan daerah absorpsi untuk C-H (alkana). Pita serapan sedang pada rentang bilangan gelombang 1750-1730 $\mathrm{cm}^{-1}$ menunjukkan adanya vibrasi ulur $\mathrm{C}=0$ pada ester. Pita serapan kuat pada rentang bilangan gelombang 1725 $1705 \mathrm{~cm}^{-1}$ menunjukkan adanya vibrasi ulur untuk $\mathrm{C}=0$. Pita serapan kuat pada bilangan gelombang 1464,63 $\mathrm{cm}^{-1}$ yang sedang mengindikasikan adanya vibrasi ulur gugus $\mathrm{C}-\mathrm{H}$ metilen. Pita serapan kuat pada rentang bilangan gelombang 1300-1000 $\mathrm{cm}^{-1}$ menunjukkan adanya vibrasi ulur C-O. Berdasarkan hasil analisis FTIR tersebut dapat dikatakan bahwa komponen $\mathrm{B}$ memiliki gugus fungsional $\mathrm{C}=\mathrm{O}$ ester , $\mathrm{C}-\mathrm{O}$ ester dan terdapat ikatan $\mathrm{C}=\mathrm{C}$.

Uji Aktivitas Antibakteri terhadap Bakteri Escherichia coli dan Staphylococcus aureus dilakukan pada Fraksi I yang dilarutkan dalam aseton, Fraksi II dilarutkan dalam metanol, dan Komponen $B$ dilarutkan dalam heksana. Pelarut aseton, metanol, dan heksana digunakan sebagai kontrol negatif, sedangkan untuk kontrol positif digunakan ampisilin. Uji aktivitas antibakteri dilakukan dengan metode sumuran. Bakteri Escherichia coli dan Staphylococcus 
aureus diinokulasikan pada permukaan media. Permukaan media kemudian di bor untuk membuat sumuran menggunakan alat yang memiliki diameter $6 \mathrm{~mm}$. Dan dimasukkan sampel sebanyak $20 \mu \mathrm{L}$. Media yang berisi sampel uji kemudian diinkubasi selama 24 jam pada temperatur $37{ }^{\circ}$ C.Media agar yang telah diinkubasi selama 24 jam diukur zona beningnya menggunakan jangka sorong. Diameter zona bening yang terbentuk menunjukkan daya hambat sampel terhadap bakteri yang diujikan. Uji aktivitas pada Fraksi I dilakukan dengan cara melarutkan $50 \mathrm{mg}$ sampel dalam $10 \mathrm{~mL}$ aseton untuk membuat larutan dengan konsentrasi 5000 ppm. Uji aktivitas pada Fraksi II dilakukan dengan cara melarutkan $50 \mathrm{mg}$ sampel dalam $10 \mathrm{~mL}$ metanol untuk membuat larutan dengan konsentrasi $5000 \mathrm{ppm}$. Uji aktivitas pada Komponen $B$ dengan melarutkan $25 \mathrm{mg}$ sampel dalam $5 \mathrm{~mL}$ heksana untuk membuat larutan dengan konsentrasi 5000 ppm. Hasil uji aktivitas antibakteri pada Fraksi I, Fraksi II, dan Komponen B ditunjukkan pada Tabel 5.

Tabel 5 Hasil Uji Aktivitas Antibakteri pada Fraksi I, Fraksi II, dan Komponen B.

\begin{tabular}{|c|c|c|c|c|c|}
\hline \multirow{2}{*}{ Sampel } & \multicolumn{3}{|c|}{ Zona Bening Bakteri (mm) } & \multirow{2}{*}{$\begin{array}{l}\text { Rata-rata } \\
(\mathrm{mm})\end{array}$} & \multirow{2}{*}{$\begin{array}{l}\text { Aktivitas } \\
\text { Antibakteri }\end{array}$} \\
\hline & 1 & 2 & 3 & & \\
\hline Fraksi I (EC) & 14,750 & 14,300 & 13,850 & 14,300 & tinggi \\
\hline Fraksi I (SA) & 16,350 & 15,500 & 15,450 & 15,760 & tinggi \\
\hline Fraksi II (EC) & 17,550 & 17,300 & 18,700 & 17,850 & tinggi \\
\hline Fraksi II (SA) & 15,000 & 15,200 & 13,550 & 14,590 & tinggi \\
\hline Komponen B (EC) & 8,250 & 8,250 & 8,000 & 8,160 & sedang \\
\hline Komponen B (SA) & 8,250 & 7,000 & 8,700 & 7,980 & sedang \\
\hline
\end{tabular}

Keterangan $\mathrm{EC}=$ E.coli, dan $\mathrm{SA}=S$. aureus .

Tabel 5 menunjukkan bahwa Fraksi I memiliki diameter zona bening sebesar 14,300 mm pada bakteri Eschericia coli dan sebesar $15,760 \mathrm{~mm}$ pada bakteri Staphylococcus aureus, yang menandakan aktivitas Fraksi I sebagai antibakteri kategori tinggi. Fraksi II memiliki diameter zona bening sebesar 17,850 mm pada bakteri Eschericia coli dan sebesar 14,590 mm pada bakteri Staphylococcu aureus yang menandakan aktivitas Fraksi II sebagai antibakteri kategori tinggi. Komponen B memiliki diameter zona bening sebesar 8,160 mm pada bakteri Eschericia coli dan sebesar 7,980 mm pada bakteri Staphylococcu aureus yang menandakan aktivitas Komponen B sebagai antibakteri kategori sedang.

\section{Simpulan}

Ekstrak aseton biji mangga golek (Mangifera indica Linn) (Fraksi II) berupa cairan kental berwarna kuning kecoklatan; larut dalam air, metanol, etil asetat, sedikit larut dalam kloroform, dan tidak larut dalam heksana; positif pada uji fenolik, flavonoid, terpenoid, saponin, dan tanin; serta memiliki aktivitas sebagai antibakteri kategori tinggi. Hasil karakterisasi pada Komponen $B$ diperoleh padatan putih dengan titik lebur $41-43^{\circ} \mathrm{C}$; memiliki ikatan ganda; Larut dalam heksana, kloroform, etil asetat, dan tidak larut dalam metanol; positif uji saponin; memiliki $\lambda_{\text {maks }} 224,20 \mathrm{~nm}$ dan $\lambda_{\text {maks }} 338,60 \mathrm{~nm}$; memiliki gugus fungsional $\mathrm{C}=\mathrm{O}$ ester , $\mathrm{C}-\mathrm{O}$ ester dan terdapat ikatan $\mathrm{C}=\mathrm{C}$; serta memiliki aktivitas sebagai antibakteri kategori sedang. 


\section{Daftar Rujukan}

Abdalla, A. E., Darwish, S. M., Ayad, E. H., \& El-Hamahmy, R. M. (2007). Egyptian mango by-product 1. Compositional quality of mango seed kernel. Food chemistry, 103(4), 1134-1140.

Cavalieri, S. J., Harbeck, R. J., McCarter, Y. S., Ortez, J. H., Rankin, I. D., Sautter, R. L., ... \& Spiegel, C. A. (2005). Manual of antimicrobial susceptibility testing. American Society for Microbiology. Pan American Health Organization: Washington, DC, USA.

Cowan, M. M. (1999). Plant products as antimicrobial agents. Clinical microbiology reviews, 12(4), 564-582.

Edewor, I. K. (2013). Spectroscopic determination of total phenolic and flavonoid contents, and antioxidant activity, of the leaves of persea americana. International Journal of Pharmacy And Pharmaceutical Sciences. Nigeria: Ladoke Akintola University of Technology.

Edeoga, H. O., Okwu, D. E., \& Mbaebie, B. O. (2005). Phytochemical constituents of some Nigerian medicinal plants. African journal of biotechnology, 4(7), 685-688.

Kabuki, T., Nakajima, H., Arai, M., Ueda, S., Kuwabara, Y., \& Dosako, S. I. (2000). Characterization of novel antimicrobial compounds from mango (Mangifera indica L.) kernel seeds. Food chemistry, 71(1), 6166.

MSDS. (2013). Acetone MSDS. (Online), retrieved 2017, 16 Mei from http://www.sciencelab.com/msds.php?msdsld=992-7062

Nuria, M.C., Faizatun, A., \& Sumantri. (2009). Uji antibakteri ekstrak etanol daun jarak pagar ( Jatropha cuircas L) terhadap bakteri Staphylococcus aureus ATCC 25923, Escherichia coli ATCC 25922, dan Salmonella typhi ATCC 1408. Jurnal Ilmu - ilmu Pertanian. 5: 26 - 37.

Roopalatha, U.C. \& Nair, V.M. (2013). Phytochemical analysis of successive reextracts of the leaves of Moringa oleifera Lam. International Journal of Pharmaceutical Science. 5:629-634.

Sari, F.P. \& Sari, S.M. (2011). Ekstraksi zat aktif antimikroba dari tanaman yodium (Jatropha multifida Linn) sebagai bahan baku alternatif antibiotik alami. Fakultas Teknik Universitas Diponegoro, Semarang.

Tian, F., Li, B., Ji, B., Yang, J., Zhang, G., Chen, Y., \& Luo, Y. (2009). Antioxidant and antimicrobial activities of consecutive extracts from Galla chinensis: The polarity affects the bioactivities. Food chemistry, 113(1), 173-179. 